\title{
ECONOMIC INTELLIGENCE ANALYSIS WITHIN THE ITALIAN BANKING SYSTEM
}

\author{
Adami Carlo ${ }^{1}$
}

\begin{abstract}
The purpose of the present article is to explore and investigate on the nature of the web of relations of the main Italian banks, on the basis of the evolution of the career paths of their relative members of the Board of Directors. The practical implications of the study is associated with the fact that there is a stronger attention by the national and international financial authorities, such as the European Central Bank (ECB) and the National Competent Authorities (NCAs), about the governance in the banks and the theoretical background and practical abilities of the senior management to assume a specific role in a financial institution. That condition determines a situation in which a member of the board of a European bank tends to have previous job experiences from other financial institutions, which can be used as informal liaisons to gathering information and disseminate knowledge, thus shaping the whole banking infrastructure. For that reason, due to the significant consequences of that bond of relations in shaping the entire financial system, the subject of the research consists in trying to measure the Economic Intelligence aptitudes of the most significant Italian banks, which derives from personal relationships constructed and developed by the senior management of the financial intermediaries in their previous job experiences. The novelty of the present article consists in conducting an Economic Intelligence analysis within the Italian banking system. Methodology. By calculating the main centrality indexes (among those offered by the Social Network Analysis discipline) related to each Italian bank within the global banking network constructed on the basis of personal relationships among the relative members of the Board of Directors, it is possible to measure a financial institution's inclination to have a sort of "influence" in the system, and in the process, to adopt a potential sound and proper Economic Intelligence strategy. The basic result of the paper highlights that, notwithstanding the dimension of a financial institution in the network, a bank could be characterized by significant centrality indexes in a web of social relations, thus having the potential capability to have a certain influence and impact within the entire banking network. In other words, the size of the bank, expressed for example as number of branches, total assets or number of employees, is not the only element to express the capacity of a bank to play a pivotal role in the financial system.
\end{abstract}

Key words: economic intelligence, banking; social network analysis, financial system, strategy, governance.

JEL Classification: F50, G21

\section{Introduction}

With the establishment of the Single Supervisory Mechanism and the beginning of the banking supervision, the European Central Bank (ECB) has introduced some underlying rules and regulations to be fully harmonized across all the countries belonging to the Eurosystem organization, in order to ensure the highest standards in fit and proper supervision.

In general, the Capital Requirements Directive IV - CRD IV (Directive 2013/36/EU of the European Parliament and of the Council) and the guidelines on the suitability of members of the management body provided by the European Banking Authority - EBA (Joint ESMA and EBA Guidelines on the assessment

\footnotetext{
Corresponding author:

${ }^{1}$ Taras Shevchenko National University of Kyiv, Ukraine.

E-mail: adami.carlo@gmail.com

ORCID: https://orcid.org/0000-0002-1603-0947
}

of the suitability of members of the management body and key function holders under Directive 2013/36/EU and Directive 2014/65/EU) aim to promote a level playing field in the assessment of board members, being those rules not directly applicable in each national legal system of the countries belonging to the Eurosystem, but needing to be transposed into national law.

In particular, one of the most significant criteria for the fit and proper assessment is represented by an adequate level of banking experience, showing that the potential candidate has the theoretical background and practical capabilities to assume a specific role in a bank. If the former can be demonstrated by means 
and adequate level of academic knowledge in the banking and economics fields, the latter is generally associated with a recent and significant experience in the banking industry. As a consequence, a relevant component of the members of the board of directors of banks located in a European country belonging to the Eurosystem possesses a previous experience in one or more financial institutions.

That specific situation generates an interesting web of informal connections among different banks, based on dissimilar social and personal relations between members of their Boards of Directors following previous working experience. Those connections could constitute potential communication channels among distinctive financial institutions for transmitting information, transferring code of conducts or models for conducting banking activities, and unconventional instruments (alternative to the control deriving from strategic and commercial agreements or equity ownerships) to "influence" other banks.

The Economic Intelligence (Clerc, 1997) is a new discipline introduced by academicians, which deals with the capacity of an organization to create situations of informative asymmetry and take advantage from them in the more competitive environment following the development of the globalization (Csurgai, 1998). The basic idea consists on the fact that by creating new information channels to gather data and knowledge, and exploiting such sources to disseminate information, an organization (a bank, for the purpose of the present article) can be able to occupy a best position to influence the whole network (Starostina, Adami, 2016). Such prominent position can determinate, for example, significant advantages in terms of conducting banking alliances, finalizing valuable mergers, succeeding in the funding competitions.

The aim of the research is to explore and investigate on the nature of the web of relations of the main Italian banks implemented on the basis of the evolution of the careers' paths of the members of the relative Board of Directors.

The purpose of this article consists precisely in measuring the predisposition of a bank to potentially "influence" the rest of the financial system, by quantifying the significance of the position of each banking entity in the web of social relations constructed on the basis of the previous working experience of its board of directors' members, by computing some of the main centrality indexes of the network. A significant central position of a bank in the network constitutes a situation of potential advantages versus other financial institutions, in terms of capability to have further communication channels to collect information, transfer knowledge and provide influence.

\section{Literature review}

Numerous academic and professional studies have been conducted in the financial field focusing on the interconnections among banks, with the main purpose of preventing money laundering (Colladon, Remondi, 2017), or managing systemic risks under macroeconomic distress (Hyun Jo, 2012). The attention, in fact, is generally focused in exploring the bank's social relations in order to estimate the global resilience of the financial market to support and sustain a financial crisis (Morales, Brizan, Ghaly, Hauner, Ma, Reza, Rosenberg, 2014).

The better part of the investigations tends to use financial relationships as a driver for representing the linkage among banks in the network, such as cross-border banking flows (Minoiu, Reyes, 2013) or bilateral interbank positions (Affinito, Pozzolo, 2017). Different researches, however, adopted a different factor for quantifying bank interrelations (Rönnqvist, Sarlin, 2016).

More interesting, according to the purpose of this paper, some papers have analysed the interlocking directorships in the banking director network, thus demonstrating the existence of a highly connected social system, based on personal relationships among the apical positions in the banking sector, able to influence many other industries, including healthcare, mining and education (Senekal, Stemmet, 2014).

Instead, the present study is focused on the analysis of the network of social relation among members of the Board of Directors of the Italian bank, deriving by contacts developed in their previous personal professional experience in other financial institution, thus representing a novelty in the academic literature.

\section{Methodology}

The methodology used to conduct the Economic Intelligence analysis within the Italian banking system and, in the process, to identify and measure the financial institution's inclination to have a sort of "influence" in the system, and to adopt a potential sound and proper Economic Intelligence strategy is based on the Social Network Analysis (SNA) (Wasserman, Faust, 1994). The SNA is a modern discipline used for the study of social relationships, applied in different areas of the social sciences: economics, public relations, sociology, maths, politics, anthropology. That specialty has its roots in the graph theory (Gross, Yellen, Zhong, 2014), a method for developing and modelling some specific problems, introduced by the mathematician Leonhard Euler with the aim to find a solution for the problem of the seven bridges of Königsberg. The fundamental element of the graph theory is the graph, a discrete object able to describe in a simplistic way, by means of quantitative or algorithmic approaches, more complex 
situations (Adami, 2019). The use of the graph theory within the social networks (Harary, 1964) consists in conceptualisation of a group of actors (for the purpose of this paper: banks) as an ideal structure composed by a set of entities (represented by nodes) connected with relations (epitomized by arches or links connecting pairs of units). As a consequence, a social structure as the one made by the interrelations of social nature (professional liaisons due to previous career's paths) among organizations or individuals (banks and their relative members of the Board of Directors), can be depicted as a social network, that is a graphical representation of the articulated web of interactions. That more schematic representation can be observed and analysed in its dynamics by using specific indexes which are able to evaluate and measure the importance of each entity and its contacts within the whole network.

In the present article, the potential social relations among members of the Board of Directors of the main Italian banks, constructed during their previous personal careers' paths, is used as basic network for quantifying the significance of the position of the banks within the whole financial system. In particular, by analysing all the curricula of all the directors of the main Italian banks officially published and freely available on the web, some information about previous banking experiences in other financial institution have been extrapolated and used to build an adjacency matrix to be used for the creation of the banking network.

Due to the fact that a bank characterized by a central place in the network of the social relations of the respective members of the Board of Directors would be in a better position for adopting a sound and proper Economic Intelligence strategy (that is implement a methodological approach of gathering and disseminate information), the centrality indexes will be taken into consideration as indicators of the stance of each financial intermediary.

In the specific, the following four centrality indexes are computed for the purpose of the analysis: the degree centrality, the closeness centrality, the betweenness centrality and the eigenvector centrality.

The degree centrality is defined as the number of ties owned by a node, that is, in the Italian banking network, the number of direct social relations of the members of the Board of Directors of a bank, with the other banks, deriving from a previous work experience in such institutions. As a consequence, the bank that is characterized by the higher degree of centrality is also the one in which the senior directors have the greater number of reciprocal relationships with the rest of the banking system and, in the process, a greater ability to collect valuable data and information concerning their competitors, and influence the credit industry.

Instead, the closeness centrality is another index of centrality that measures the average of the distance of a node from all the others. It means that whereas the degree centrality focuses only in the direct links, the closeness centrality also takes into consideration the indirect ones. According to the meaning generally attributed to the latter index, it provides a measure of the ability of a bank to enter in contact with the whole financial system, through the fewest possible intermediaries.

The betweenness centrality refers to the extent to which a node is positioned on paths among other vertices. A high value of that centrality index, in fact, express a valuable influence within a network by virtue of their control over information passing between others. The importance of the indicator is associated to the fact that a bank characterized by a significant betweenness centrality index constitutes a bridge among two or more subnetwork in the banking web of relations, and its removal will cause a destructive effect on the whole financial system (loss of communication channels between other banks).

The last index analysed in the present article is the eigenvector centrality, a ranking measure originally developed by Wassily W. Leontief (Kuznets, 1941), which identifies the nodes with a strong and direct bond with vertices characterised by a high degree centrality. In fact, not all links have the same weight, and the eigenvector centrality appraises the value of each of them. Thus, a bank with a strong liaison with one or more financial institution having a high degree centrality, would be able to have indirectly a significant influence in the network.

The computation of the four different centrality indexes above illustrated has been conducted using an open-source cross-platform software application for social network analysis and visualization called "Social Network Visualizer (SocNetV)". Such software is developed in $\mathrm{C}++$ and runs on different operating systems (Linux, OS X, Windows). Thanks to its graphical user interface it is possible to construct and display the social networks in different layouts, which allow to better understand the main features of the web of relations.

In particular, the board of directors career' paths have been converted in a social network by means of the creation of an adjacency matrix. In the specific, each relation among two actors(x;y) (in our case, banks) is equal to 1 in case of the existence of an edge from actor $x$ to actor $y$ (that is the bank $x$ has a director with a previous experience in the bank y), or equal to 0 if there is no connection between the actors (no director belonging to bank $\mathrm{x}$ has a previous experience in the bank $\mathrm{y}$ ). The adjacency matrix is then imported in the SocNetV and drawn as graph, where vertices depict the banks and edges represent the personal and social relations related to previous experiences of the members of the board of directors. 
Table 1

Example of Adjacency Matrix

\begin{tabular}{|c|l|l|l|l|l|l|l|l|l|l|}
\hline Actor/ Actor & 1 & 2 & 3 & 4 & 5 & 6 & 7 & 8 & 9 & 10 \\
\hline 1 & 0 & 0 & 0 & 0 & 0 & 0 & 0 & 0 & 0 & 0 \\
\hline 2 & 1 & 0 & 0 & 0 & 0 & 0 & 0 & 0 & 0 & 0 \\
\hline 3 & 0 & 0 & 0 & 0 & 0 & 0 & 0 & 0 & 0 & 0 \\
\hline 4 & 1 & 0 & 1 & 0 & 0 & 1 & 0 & 0 & 0 & 0 \\
\hline 5 & 1 & 0 & 0 & 0 & 0 & 1 & 0 & 0 & 0 & 0 \\
\hline 6 & 0 & 0 & 0 & 0 & 1 & 0 & 0 & 0 & 0 & 0 \\
\hline 7 & 1 & 1 & 1 & 0 & 1 & 0 & 0 & 0 & 0 & 0 \\
\hline 8 & 1 & 0 & 1 & 0 & 1 & 1 & 1 & 0 & 0 & 0 \\
\hline 9 & 0 & 0 & 0 & 0 & 0 & 0 & 0 & 0 & 0 & 0 \\
\hline 10 & 0 & 0 & 1 & 0 & 0 & 0 & 0 & 0 & 0 & 0 \\
\hline
\end{tabular}

Source: Author's own research

\section{Empirical results}

As stated above, the research conducted in this paper is focused on the network of the social relations among the main Italian banks, constructed taking into consideration the previous experiences of the current members of the board of directors (the year considered is 2020) in other financial institutions represented in the network.

In Table 1, a list of the banks contemplated in the analysis is depicted. In particular, it is worth to highlight that the investigation is focused only on the Italian banks network, and for that reason the foreign financial institutions play a passive role in the web of relations. In other words, the social connections below illustrated are the result of the links among banks resulting from an assessment of only the curricula and previous experiences related to the directors belonging to Italian banks encompassed in Table 2.

In Figure 1, the basic layout of the network of social interconnections among the banks is constructed. The nodes characterize the different financial institutions, and each number associated to each node identifies a specific bank, following the order presented in the list of Table 1 . Thus, for example, the nodes number 1,2 and 3 represent respectively Unicredit Group (UCG), Monte Paschi di Siena (MPS) and Intesa, whereas the nodes number 38,39 , and 40 epitomise correspondingly Commerzbank, Credit Agricole and Ing Bank. The direction of the arrow epitomizes the relations deriving from previous experiences of a director belonging to the bank from the which the arrow starts, in a bank where the arrow indicates. Thus, for example, the arrow on the top moving from the node 4 to the node 20 implies that there is at least a director in Fineco Bank (4) with a previous experience in BNL-BNP Paribas (20).

In order to have a better graphical representation of the values of the four centrality indexes illustrated in the previous paragraph, in Figures 2, 3 and 4, four different depictions of the network are showed. In particular, in each representations the layout of the network is proposed to highlight each specific centrality index taken into consideration for the analysis: the bank with a higher value of such specific index is symbolized by a larger size of the ball, and positioned in the center of the ideal radial scheme.

By looking at Figure 2, it appears clear that BPER (8) turns out to result the bank with the higher degree centrality index, followed by Fineco (4), Mediobanca (5), and Banco BPM (7), which complete the more central cluster. On the other hand, Unicredit (1), MPS (2) and Intesa (3) seem to be characterized by a low value for such index. All the foreign banks are depicted with the smaller size of the balls and on the border (due

Table 2

Legend of the Bank/Node

\begin{tabular}{|c|r|c|r|c|r|c|r|}
\hline 1 & UCG & 11 & Banca Generali & 21 & Chase Manhattan Bank & 31 & Group BPCE \\
\hline 2 & MPS & 12 & Banca Pop Sondrio & 22 & Barclays & 32 & UBC \\
\hline 3 & INTESA & 13 & Banca Profilo & 23 & Morgan Stanley & 33 & Merril lynch \\
\hline 4 & Fineco Bank & 14 & Banca Sisstema & 24 & Citigroup & 34 & Goldman Sach \\
\hline 5 & Mediobanca & 15 & Credito Valtellinese & 25 & Dresdner Bank & 35 & Banco DESIO \\
\hline 6 & Banca Mediolanum & 16 & Illimity Bank & 26 & Banca Intermobilliare & 36 & JP Morgan \\
\hline 7 & Banco BPM & 17 & Banca Carige & 27 & Nomura & 37 & RBS \\
\hline 8 & BPER & 18 & Societe Generale & 28 & Natexis & 38 & Commerzbank \\
\hline 9 & Credito Emiliano & 19 & Credit Suisse & 29 & Deutsche Bank & 39 & Credit Agricole \\
\hline 10 & Banco Finnat & 20 & BNL-BNP Paribas & 30 & HSBC & 40 & ING Bank \\
\hline
\end{tabular}

Source: Author's own research 


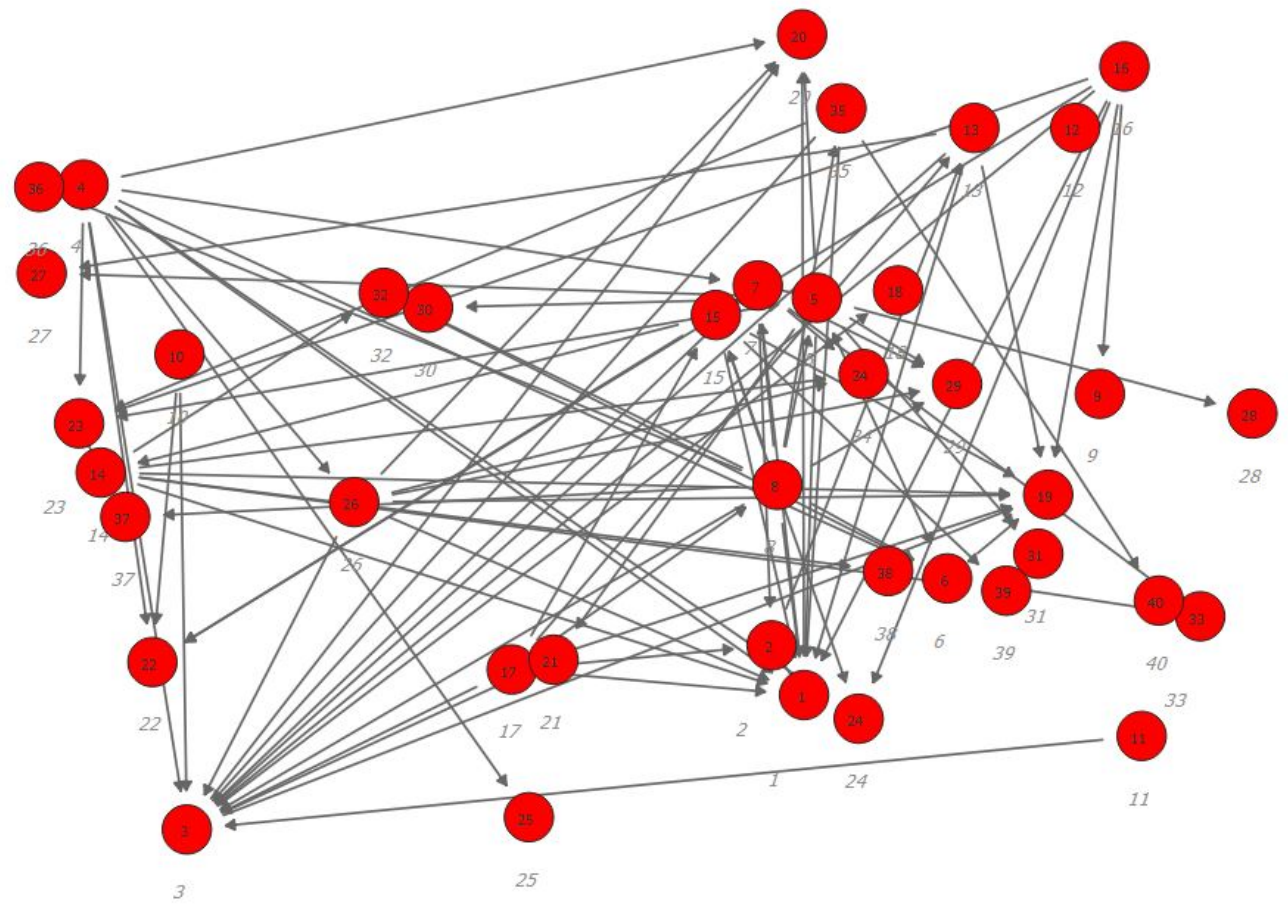

Figure 1. Social Relation Network of the Main Italian Banks

Source: Author's analysis

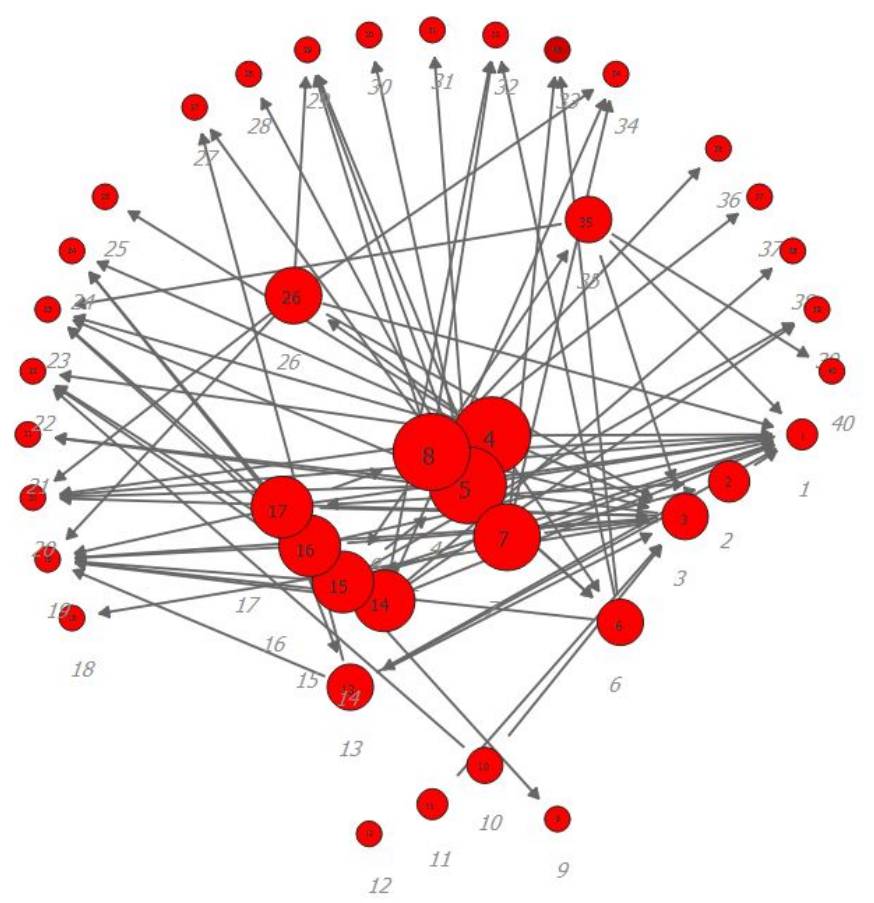

Figure 2. Degree Centrality Indexes of the Main Italian Banks

Source: Author's analysis

to a value of the degree centrality index equal to zero) in consideration of the fact, as above described, nonItalian banks are considered only as passive actors (the curricula of their respective directors are not considered for developing the web of relations).
The specific result illustrated in Figure 2 could be justified by taking into consideration that the members of the Board of Directors of the middle-sized banks tend to have previous working experience in other financial institutions. Instead, members of the Board 
of Directors of the most significant bank (Intesa, Unicredit and MPS) have mainly an academic or institutional background, or tend to possess banking experience developed internally. According to such interpretation, Banco BPM appears to be as an outlier, probably due to the fact it became the third Italian bank only recently (in 2017) following the merger between to middle-sized banks, thus maintaining some typical features in terms of organization and governance typical of medium sized banks.

Instead, in Figure 3, the design of the network is aimed to provide information on another centrality indexes: the closeness centrality (again highlighted by the size and the radial explosion of the nodes). In this case, differently from the previous picture, a unique bank located in a central position emerges: Unicredit (1). The second place on the podium, with respect this specific centrality index, and with a significant gap in terms of distance from the first position, is occupied by Intesa (3).

Taking into consideration that the closeness centrality index measures the ability of a bank to enter in contact with the whole financial system, a possible clarification of such result is represented by the ability of Unicredit (and of Intesa in minor extent) to "influence" the Italian banking network, for example, by setting some standards or introducing new models for conducting the bank activity. That ability is associate to the fact that Unicredit and Intesa constitutes the most common previous professional experience of the members of the board of directors of the Italian banks examined.
By looking at Figure 4, it is possible to affirm that there is not a clear limited cluster: there are, in fact, six banks that cover a more central position: Mediobanca (5), BPER (8), Intesa (3), Carige (17), Creval (15), and Banco BPM (7). Being the centrality indexes relative measures of the stance of a node in the network, the result in this case does not provide interesting information to express considerations on the potential capacity of the banks to "influence" the system.

The reason of the specific pattern of the network (according to the beetweenness index, which should identify the potential bridges among subnetworks) is probably linked to the fact that there are not significant and well delineated subnetworks (due in part to a limited absolute number of banks taken into consideration for the investigation).

In particular, only two cliques (largest subgroup of banks in the social network, which are all directly connected to each other) result from the network: the first one is constituted by Mediobanca (5) and Banca Mediolanum (6); the second one is composed by MPS (2) and Carige (17). It is remarkable that the last cluster (maximal complete subgraph) encompasses the two Italian defaulted banks. Finally, a different layout of the network is proposed, with the aim to highlight the eigenvector centrality indexes for each bank of the network, that is the measure of the closeness to the banks characterized by a high degree centrality (BPER, followed by Fineco, Mediobanca, and Banco BPM). The banks with the highest eigenvector centrality indexes are: Carige (17) and MPS (2), the two defaulted Italian banks.

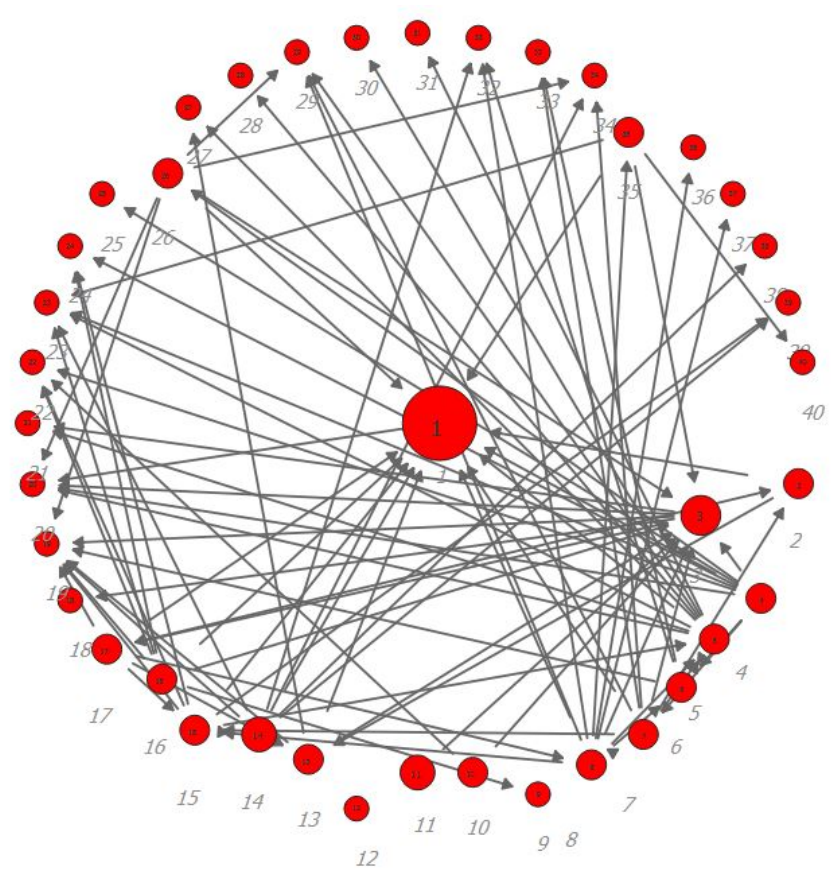

Figure 3. Closeness Centrality Indexes of the Main Italian Banks

Source: Author's analysis 


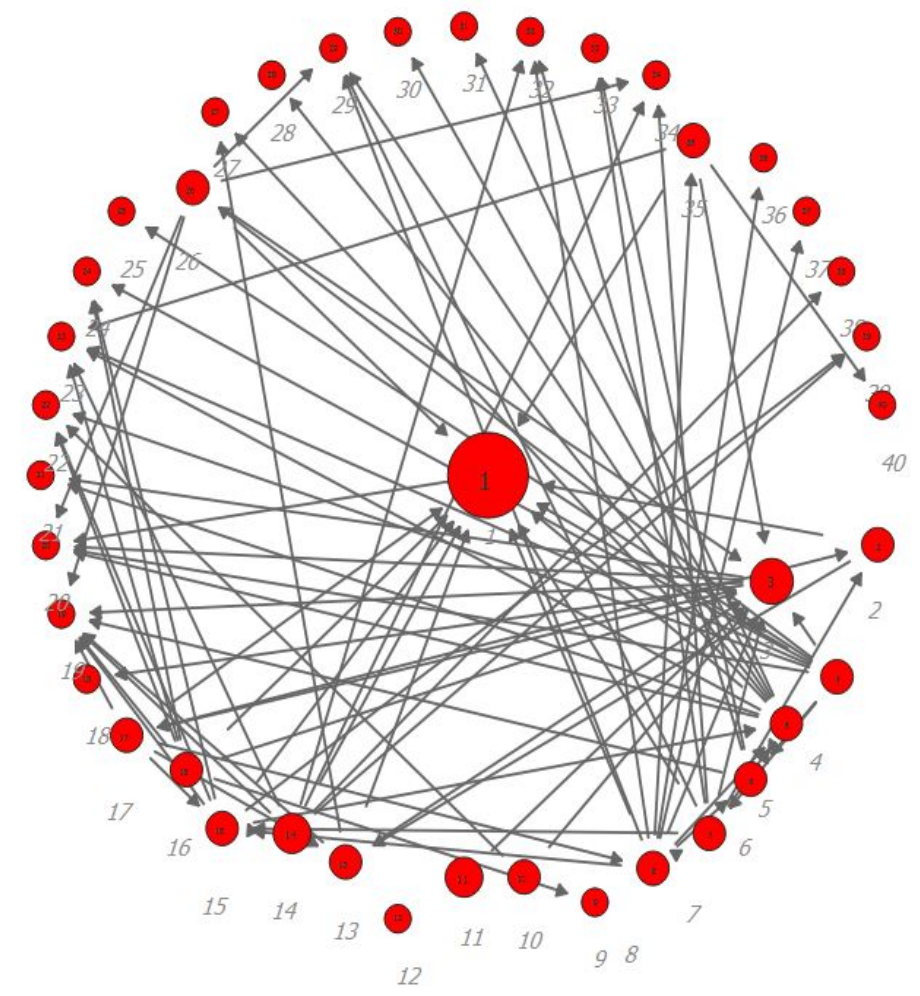

Figure 4. Betweenness Centrality Indexes of the Main Italian Banks

Source: Author's analysis

\section{Conclusions}

The analysis conducted in this paper by means of the social network analysis methodology has showed how it is possible to explore and investigate on the nature of the web relations of the main Italian banks on the basis of the evolution of the career paths of their relative members of the board of directors.

The findings are remarkably interesting. In fact, the basic conclusion of the article highlights that, notwithstanding the fact that a prominent role in the banking sector is naturally occupied by the most larger banks in terms of financial assets, or branches, less significant banking institution could be still in a preferred position for developing informal communication channels to collect or disseminate information, transfer knowledge, and providing influence.

In particular, in the Italian banking system, other than the two largest banks: Unicredit and Intesa (characterized by the highest closeness centrality indexes), also BPER turns out to result the bank with the higher degree centrality index, followed by Fineco,
Mediobanca, and Banco BPM. Furthermore, due their respective high values of eigenvector centrality indexes, also MPS and Carige could have a potential influence, in terms of social relationship, on the Italian banking system. That means that indirectly, those banks could have a significant influence, in terms of social relationship, on the Italian banking system.

However, further research should be conducted in order to quantify the importance of the position of each Italian bank in the web of the social relations and its predisposition to influences the network, by identifying other different types of networks. Thus, for example, the social network analysis could be applied to the Italian banking system, by focusing on the careers' paths of the Board of the Statutory Auditors. Furthermore, the same analysis could be also conducted for other countries, in order to carry out qualitative and quantitative comparison of the different financial systems and the dissimilar Economic Intelligence aptitudes of the main banking institution.

\section{References:}

Adami, C. (2019). The Use of the Graph Theory to Investigate the Role of the Economic Intelligence for the National Security. Economic Bulletin, vol. 2(10), pp. 6-14.

Affinito, M., \& Pozzolo, A. F. (2017). The interbank network across the global financial crisis: evidence from Italy, Banca d'Italia, Temi di Discussione, Number 1118. Available at: https://www.bancaditalia.it/pubblicazioni/ temi-discussione/2017/2017-1118/en_tema_1118.pdf 
Clerc, P. (1997). Economic Intelligence, World Information Report 1997-1998, Unesco Publishing, Paris, 1997, Chapter 22, pp. 304-317.

Colladon, A. F., \& Remondi, E. (2017). Using social network analysis to prevent money laundering, Expert Systems With Applications, no. 67, pp. 49-58.

Csurgai, G. (1998). Geopolitics. Geoeconomics and Economic Intelligence, The Canadian Institute of Strategic Studies, Strategic Datalink no. 69.

Gross, J. L., Yellen, J., \& Zhong, P. (2014). Handbook of Graph Theory. Second Edition. CRC Press, Taylor \& Francis Group.

Harary, F. (1964). Applications of Graph Theory to Group Structure (Claude Flament), SIAM Review, vol. 6, no. 2, pp. 185-186.

Hyun, Jo J. (2012). Managing systemic risk from the perspective of the financial network under macroeconomic distress, Bank for International Settlement, FSI Award 2012 Winning Paper, September 2012, ISSN 1684-7180. Available at: https://www.bis.org/fsi/awp2012.pdf

Kuznets, S. (1941). The Structure of the American Economy, 1919-1929. By Wassily W. Leontief. Cambridge: Harvard University Press, 1941. Pp. xi, 181, The Journal of Economic History, 1(2), pp. 246-246. doi: 10.1017/ S0022050700053158.

Minoiu, C., \& Reyes, J. A. (2013). A network analysis of global banking: 1978-2010. Journal of Financial Stability, vol. 9, issue 2, pp. 168-184.

Michelle Renee Morales, David Guy Brizan, Hussein Ghaly, \& Thomas Hauner (2014). Application of Social Network Analysis in the Estimation of Bank Financial Strength During the Financial Crisis. Available at: https://www.researchgate.net/publication/289538675_Application_of_Social_Network_Analysis_in_the_ Estimation_of_Bank_Financial_Strength_During_the_Financial_Crisis

Rönnqvist, S., \& Sarlin, P. (2016). Bank networks from text: interrelations, centrality and determinants, ЕСB Working Paper N. 1876, January 2016. Available at: https://www.ecb.europa.eu/pub/pdf/scpwps/ecbwp1876. en.pdf

Senekal, B. A., \& Stemmet, K. (2014). The South African Banking Director Network: An Investigation Into Interlocking Directorships Using Social Network Analysis (SNA). International Business \& Economics Research Journal (IBER), 13(5), pp. 963-980. doi: 10.19030/iber.v13i5.8765

Starostina, A. O., \& Adami, C. (2016). The Role of the Economic Intelligence in the Modern International Economic Relations, in Innovations in the Development of Socio-Economic System: Microeconomic, Macroeconomic and Mesoeconomic Levels, Collective monograph, vol. 1, Izdevnieciba "Baltija Publishing", Latvia, pp. 1-15.

Wasserman, S., \& Faust, K. (1994). Social Network Analysis. Methods and Applications, Cambridge University Press, Cambridge. 